\title{
Infrastructure Study for Solving Connectivity Problems Through the Nile River
}

\author{
(A Case Study on the Assuit-Delta Reach)
}

\author{
Noha Kamal ${ }^{1}$ \\ Associate Professor \\ Nile Research Institute (NRI) \\ National Water Research Center (NWRC), Cairo, Egypt
}

\author{
Ibrahim Gomaa ${ }^{2} *$ \\ Assistant Professor \\ Computers and Systems Department, \\ National Telecommunication Institute (NTI), Cairo, Egypt
}

\begin{abstract}
Fiber optics cables present various benefits over regular cables when used as a data transportation medium in today's communication networks. It is noted that there are significant challenges in the connectivity of inner cities that are located far inland away from the coastal areas. Most of the networks developed in Africa, especially in Egypt, are connected via submarine cables flowing across coastal areas. Very few connections are constructed to connect inner cities by crossing the Nile. The Nile River is characterized by a wide area, offering a natural path for underwater cables' laying areas. In this study, the analysis and evaluation of the laying of these cables along the bed of the Nile River in Egypt, rather than crossing it, is investigated. There are many issues with laying fiber optic cables across the Nile River. Some of these are the requirement of using more than one node over fiber optic cable for each. When the number of nodes increases, the cost of installation and drilling effort increases with each node. The fiber optic cable path along the Nile River is simulated with a numerical model (Delft-3D). Two different scenarios for laying cables were applied and analyzed to evaluate the effect of the predicted water surface and sediment profiles on the fiber optic cable path. Based on the results obtained, the fiber-optic network infrastructure is proposed to solve connectivity problems by laying fiber optic cables along the Nile River.
\end{abstract}

Keywords-Communications; optical fiber cables; delft3d; underwater / river crossing cable

\section{INTRODUCTION}

Communication is very important in the life of human beings since ancient times. Underwater optical fiber communication technologies present new advancements in this field. Underwater optical fiber technology has evolved over the years and is growing at high rates [9]. Fiber-optic usage in communication networks has many advantages and disadvantages compared to electric wiring cables, especially with long distances. Fiber optics have various benefits such as high data security (since there is no electromagnetic radiation from cables), immunity to electromagnetic interference, lack of current-induced sparks risks (having no conducting current used), using small and lightweight materials, and high operating bandwidth over long distances [11]. On the other hand, these cables have some disadvantages such as cost because cables have expensive installation although they last longer than copper cables. Also, optical fibers require repeating at distance intervals, and Fragility [21] [8]. In addition to that, optical fibers require more protection around cables compared to copper [1]. Various projects aim to link Africa to the world networks through undersea fiber-optic cable networks; as shown in Fig. 1 [20]. However, there is a difficult challenge in the connectivity of inner towns and cities that are located far inland away from the coastal areas.

In Egypt; the Abu Talat city which is marked by number 1 is linked to the undersea Cables Europe India Gateway (EIG), Middle East North Africa (MENA) Cable System/Gulf Bridge International, TE North/TGN- Eurasia/SEACOM/Alexandros network systems. Alexandria city no. 2 which is connected to Cables Aletar, FLAG Europe- Asia (FEA), Hawk, IMEWE, SeaMeWe-3, and SeaMeWe-4. Suez city no.3 connected to cables FALCON, FLAG Europe- Asia (FEA), IMEWE, SeaMeWe-3, and SeaMeWe-4. Zafarana city no.4 connected to cables Europe India Gateway (EIG), Middle East North Africa (MENA), Cable System/Gulf Bridge International, SEACOM/Tata TGN-Eurasia. [20].

The objectives of this research are to study, analyze, and evaluate the laying fiber optic cables system along the bed of the Nile River in Egypt. Because of the fiber optic network characteristics and advantages, fiber-optic cables are considered an effective alternative to consider for a new communication network in long and spacious lands such as in Egypt. This is in comparison to using either satellite for telecommunication or laying copper wire coaxial cables for long distances [18].

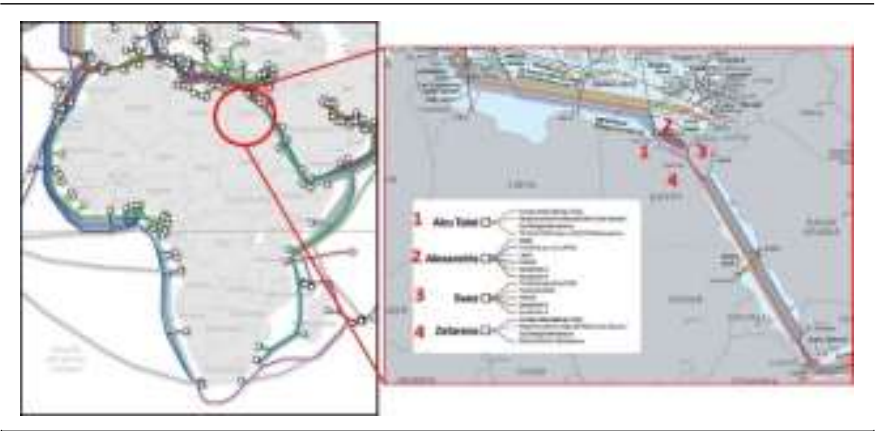

Fig. 1. Map of Africa with Coastal undersea Fiber-Optic Networks. Egypt Cable Locations are Encircled. [20].

\footnotetext{
*Corresponding Author
} 


\section{RELATED WORKS}

Several researchers have provided a detailed analysis of submarine optical fiber cable transmission systems. Ammar A. Saleh, et al. [15] study and analyze a proposal suitable for African Nile River basin countries to lay new fiber optics cable networks submerged under the river's water level. This proposal discusses the challenges that are faced by common ground cable networks. Paul D. et al. [3] provided an analysis of undersea bed fiber optic cable network that is reported on several cable networks TAT, their reliability, and cost considerations. Recently, Navneet A. and Ajay V. [12] Neal $\mathrm{S}$. Bergano [1], investigated undersea fiber optic cables that make the web worldwide. Modern cable systems installed up to last year are capable of transmitting about 1000 Gbps over each fiber pair [4]. In [7] they studied newly retiring fiber optic telecommunication cables, which offer far greater opportunities for the scientific community. Hsiang et al. [13] focused their work on the research and development of an integrated underwater environmental monitoring system, which is planned to be applied on the offshore wind farm of Taiwan. In [6] SAICi/MariPro was contracted by Alcatel TCC in Australia, to install a 240-kilometer long submarine fiber optic cable system across the Bass Strait in August 1995. This eighteen fiber cable system provided telecommunication services between mainland Australia and Tasmania for customers of TELSTKA. Jeffcoat et al. [2] introduced considerations in the design and laying of a new undersea fiber optic cable system. Jurdana et al. [14] analyzed underwater fiber-optic cables, evaluated their impact on the marine environment, and addressed possible threats to submarine cables from human activities and natural hazards. This work provided guidelines for improving the installation of cables, and also their security. Msongaleli et al. [17] inspected the disaster-aware submarine fiber-optic cable deployment process problem to minimize such expected extra costs in case of a disaster. Namihira et al. [5] studied the optical fiber submarine cables Polarization fluctuation characteristics under 8000-m deep-sea environmental conditions, optical fiber submarine cable conjunction under periodic variable tension, and the performance of cables through and after installation.

\section{STUDY AREA DESCRIPTION AND DATA COLLECTION}

To achieve the objectives of this study, the following methodology is applied as shown in Fig. 2.

1) Develop a database for fiber optic cables that cross the Nile River.

2) Determine the proposed fiber optic cable longitudinal path along Nile River using recent hydrographic survey data in 2016.

3) Use a Delft-3D numerical model to simulate two different scenarios for laying the fiber optic cable along the bed of Nile River by applying maximum and minimum flow, predict the morphological changes from the year 2016 to the year 2030, which could affect the efficiency of the fiber optic cables.

4) Evaluate and compare two different scenarios of laying fiber optic cables along the study's reach.

5) Evaluate the economic and environmental impacts of the ground cables and submerged cables under the Nile River.
6) Propose Nile River fiber-optic network infrastructure to solve the connectivity problems.

\section{A. Study Area Description}

The Nile River in Egypt mainly consists of a long singlechannel followed by two branches forming the Delta. The single channel's length is $953.5 \mathrm{~km}$ downstream Old Aswan Dam (OAD) in the south to just upstream Delta Barrages north of Cairo. The river is divided into four reaches. This paper focuses on the fourth reach as shown in Fig. 3, which is the longest and extends between Assiut and Delta Barrages covering a total distance of $408.75 \mathrm{~km}$. It is marked by having numerous natural phenomena represented in many islands' characteristics, and many bends. This study focuses on a segment from km 918 upstream Delta Barrage to $\mathrm{km} 937$ downstream OAD.

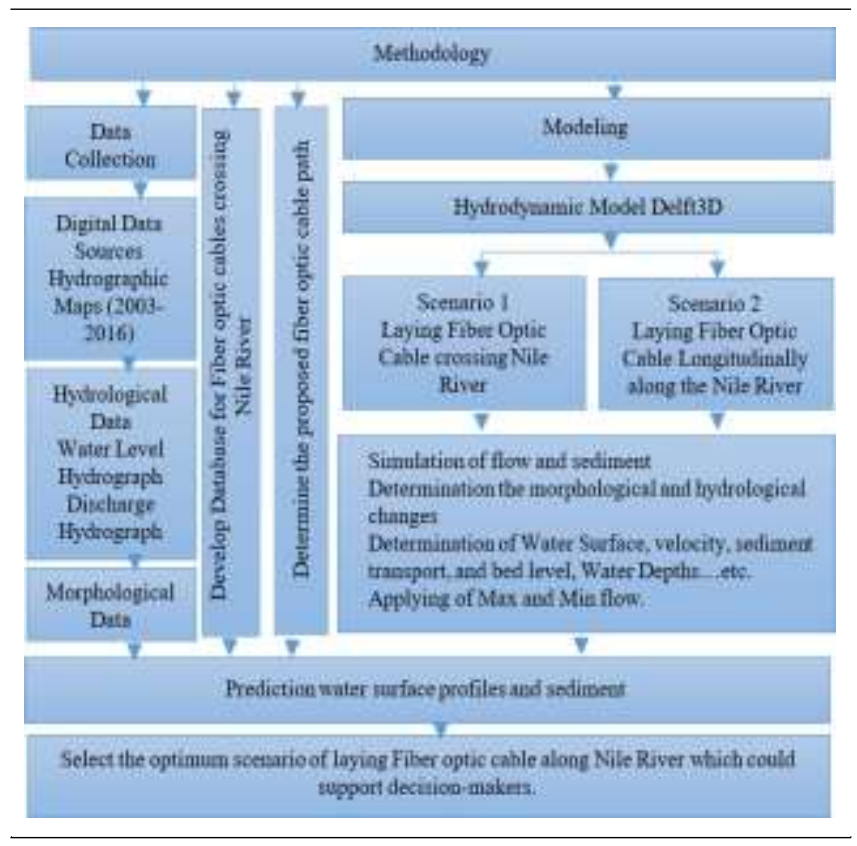

Fig. 2. Research Methodology.

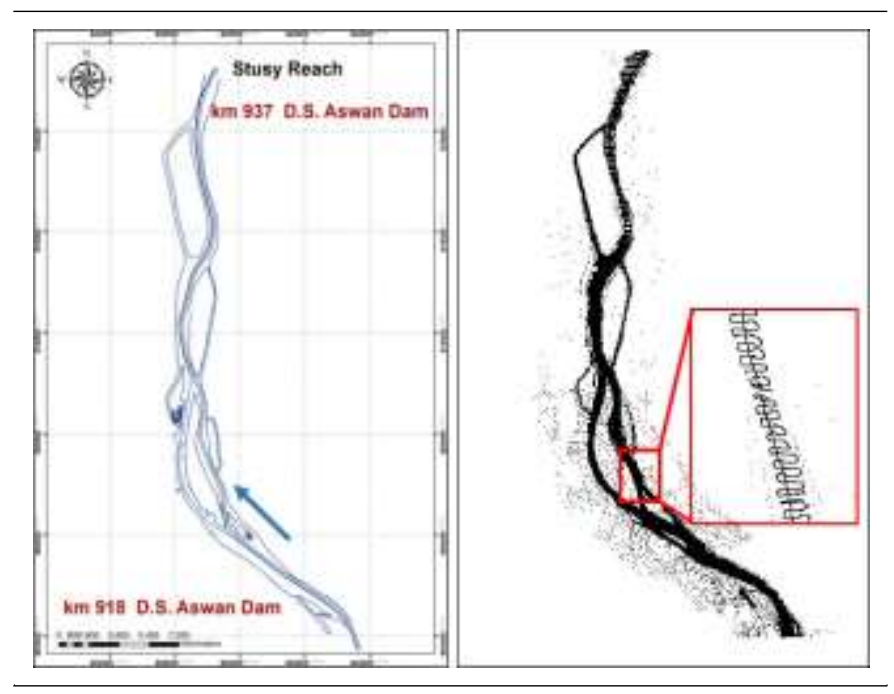

Fig. 3. Reach Location and Bathymetry Data of Study Area. 


\section{B. Data Collection}

1) Hydrographic Data: $20 \mathrm{~km}$ of the Nile River was hydrographically surveyed by the Nile Research Institute (NRI) in 2003, and 2016 respectively to reveal the riverbed morphology.

2) Hydraulic Data: the measurements of velocity were collected at the same time as the survey in 2003, and 2016. Cross-sections were selected to overlay the length of the study area. At the soil laboratory of NRI, the samples were analyzed. The results of this analysis indicated that the bed material consisted of sand and silt. The sand ranges between $95.44 \%$ and $99.07 \%$ of the bed material sample. As for the silt, it varies in the range between $0.18 \%$ and $4.43 \%$ of the bed material sample.

3) Hydrological Data: Hydrologic data is needed to initiate the model's boundary conditions. Besides, the discharge variation released through the river and its corresponding fluctuations cause a sediment transport process, which in turn, causes morphological changes through the river bed. The monthly average discharges of three years that were released downstream Assiut barrages, and the corresponding monthly average water levels have been measured at Assiut gauge station were gathered from the historical records from 2000 to 2009 as shown in Fig. 4. These three years were selected as they were distinguished by maximum and minimum flow releases respectively to represent the most critical situation that can affect the morphological characteristics of the river.

The maximum monthly average in three years of the water level and discharge of historical data from (2000-2002) and the minimum monthly average in three years of the water level and discharge of historical data from (2003-2005) are shown in Fig. 5a and 5b, and Fig. 6a and 6b.

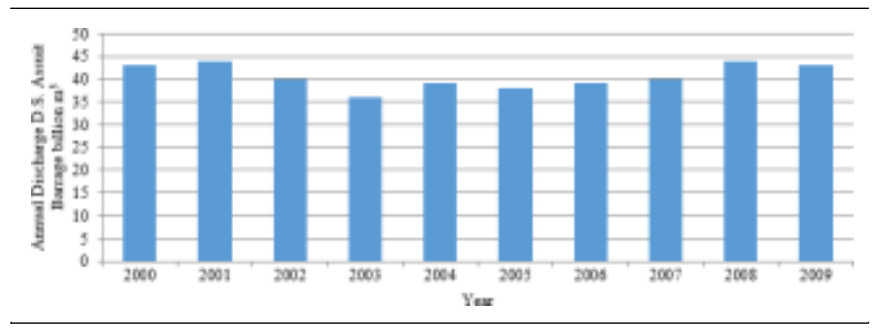

Fig. 4. River Discharge at Study Area.

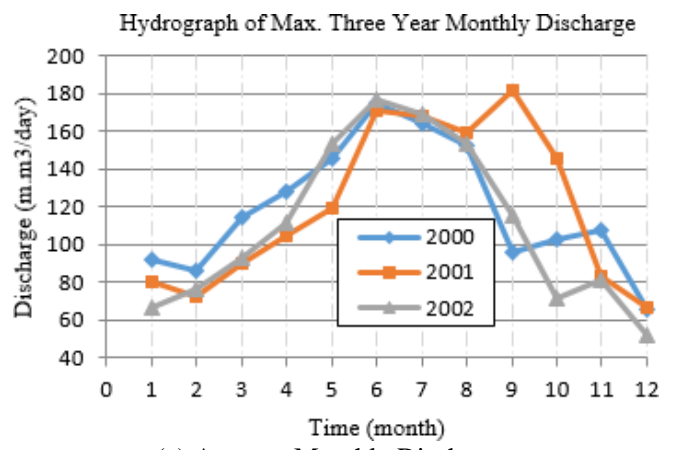

(a) Average Monthly Discharge.

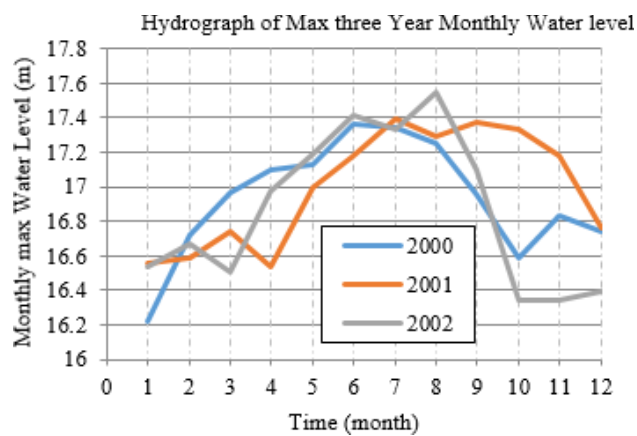

(b) Average Monthly Water Level.

Fig. 5. Nile River Hydrograph of Maximum Three Year (2000- 2002).
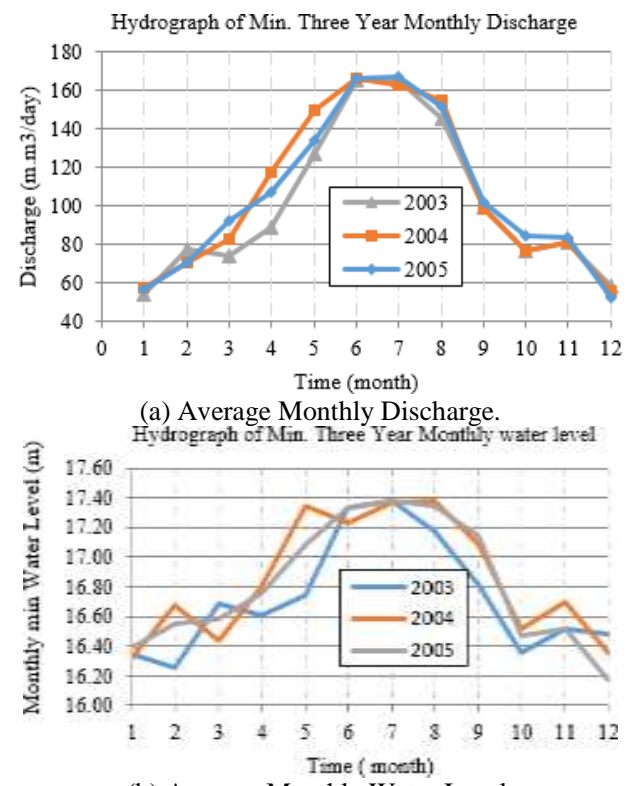

(b) Average Monthly Water Level.

Fig. 6. Nile River Hydrograph of Minimum Three Year (2003- 2005).

\section{Developing a Database for Fiber Optic Cables CROSSING THE NILE RIVER}

In this part, the development of a database is necessary and required to draw a complete picture with up-to-date information on the number and locations of fiber optic cables crossing the Nile River in Egypt. Fig. 7 shows the flexible interface of the developed database by using visual basic programming language and Geographic Information system GIS. This database stores information about all the cables.

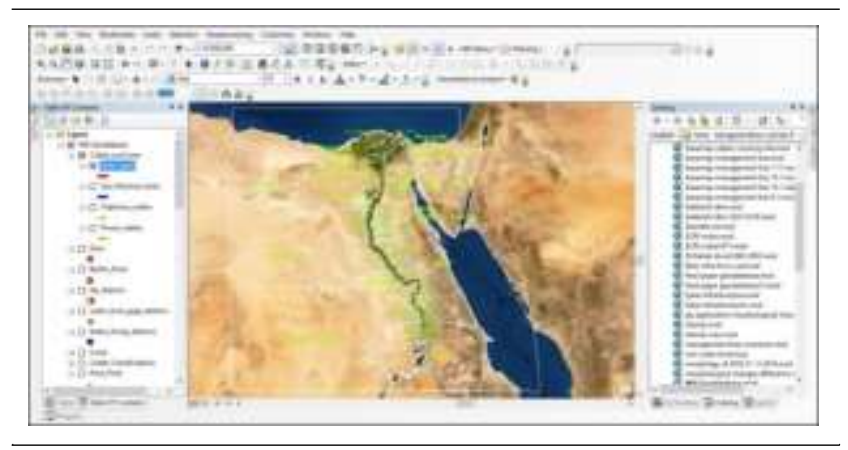

Fig. 7. Developed Database of Fiber Optic Cables Crossing Nile River. 


\section{DETERMine THE Proposed LONGITUdinAl FiBER- OPTIC CABLE PATH ALONG NILE RIVER}

By using NRI's recent hydrographic survey data from 2016, as well as the navigational path, longitudinal fiber optic cable path can be determined according to the deepest points as shown in Fig. 8. Furthermore, the calibration of that proposed path was applied by using the model shown in Fig. 9.

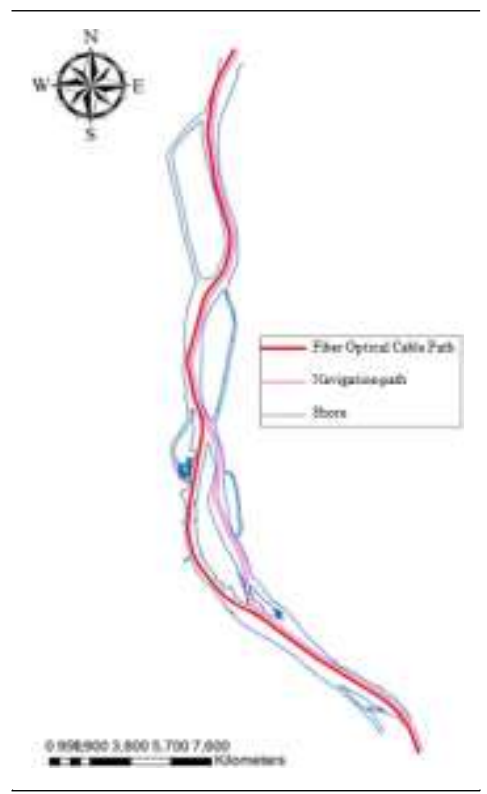

Fig. 8. Proposed Fiber Optical and Navigation Paths.

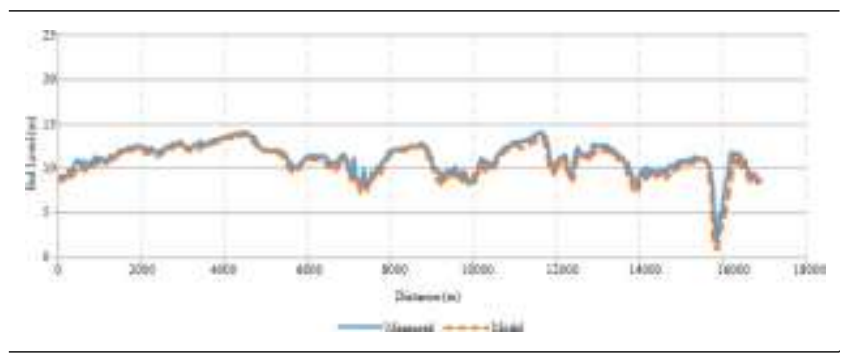

Fig. 9. Bed Level Calibration Proposed Fiber-Optic Path Longitudinal Section.

\section{NUMERICAL MODEL AND SimULATION}

\section{A. Numerical Model}

Delft3D is the hydrodynamic module of Delft3D, which is an integrated program for modeling water flows, waves, water quality, particle tracking, ecology, sediment, and chemical transports and morphology [19]. The Meyer-Peter-Muller sediment transport relation will be used [12].

1) Model preparation and grid generation: Delft3D model generated a grid network. This grid covers a distance of $18 \mathrm{~km}$ along the shoreline. A fine grid $(5 \mathrm{~m} * 5 \mathrm{~m})$ used in the model as shown in Fig. 10. The initial boundary condition is defined as the initial water levels. The initial water levels were used to simulate the flow characteristics. Both upstream and downstream boundary conditions were given to the model as inputs. The upstream boundary condition was the discharge downstream from the Assiut barrage. Also, Upstream Delta Barrage water levels were used as the downstream boundary condition.

2) Model calibration: The model calibration process was done for flow velocity distribution and also sediment transport. It can be noted that there are a sound and logical agreement between the computed and measured values of the flow velocity distributions and morphological changes at the chosen cross-sections. The model was carried out by adjusting roughness coefficients at various locations along the modeled study reach, the calibration process was run to attain the finest agreement between measured and resulted values of the model. Fig. 11 shows the velocity calibration process and velocities comparison at different cross-sections along the study area. Besides, Root Mean Square Error (RMSE) which is presented in Eq. 1 was computed to quantify the model's performance for the observed and measured bed level values [10].

$R M S E=\sqrt{\frac{\sum_{i=1}^{n}\left(X_{o b s, i}-X_{\bmod e l, i}\right)^{2}}{n}}$

Where $X_{o b s}$ is observed values and $X_{\text {model }}$ is modeled values at time/place.

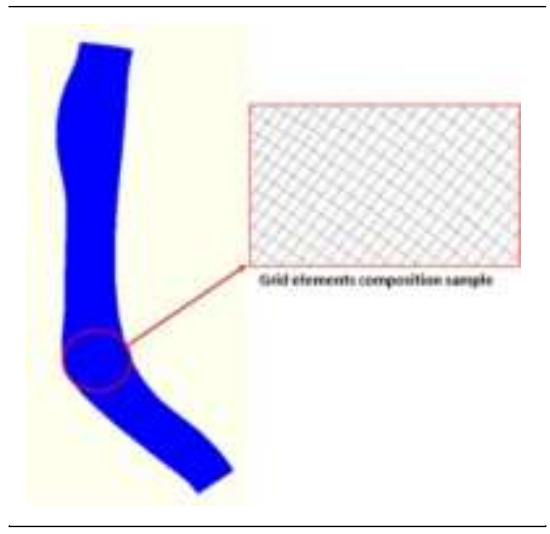

Fig. 10. Studied Reach Grid.

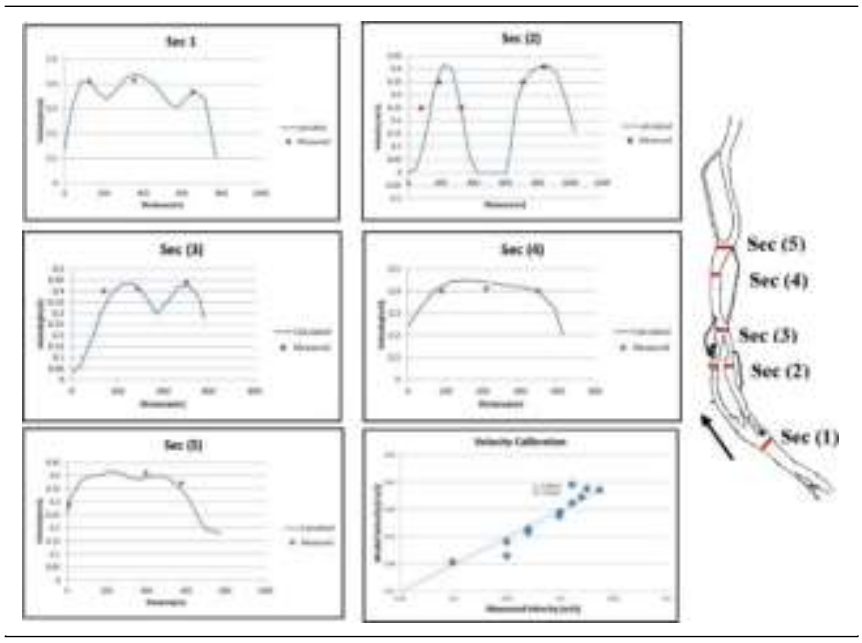

Fig. 11. The Velocity Calibration. 


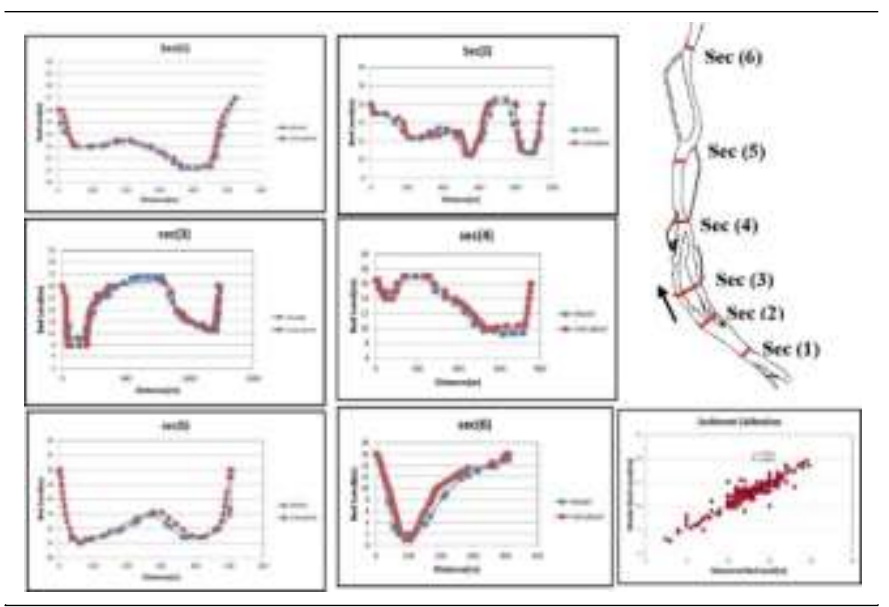

Fig. 12. The RMSE for the Observed and Measured Sediment Values.

Fig. 12 shows the calibration of the bed level and the comparison of observed and measured cross-sections through the area of study. Also, RMSE which was presented by Eq. 1 is used to quantify the model performance for the observed and measured bed level values.

3) Model simulation: The model simulated two different scenarios to achieve the main objectives of this paper. In the model simulation, the recent hydrographic survey data from the year 2016 is used to predict the morphological changes for two different scenarios of fiber optical cable path to select the optimum scenario.

a) The first scenario, fiber optical cable crossing the Nile River.

b) The second scenario is that the fiber optical cable is laid and installed along the Nile's riverbed.

These scenarios are simulated by Delft3D by applying maximum and minimum flows.

1) Scenario 1: Fiber optical cables that cross the Nile River according to our database, there are twenty-five fiber optic cables that cross the Nile River as recent as 2019. In this scenario; the Delft3D model simulation for selected fiber optic cable crossing the Nile River in the study reach is represented. The selected fiber optic cable crosses the Nile at $\mathrm{km} 928.15$ from Aswan High Dam in May 2007 as shown in Fig. 13. Also, the natural changes of the river that could affect the cable efficiency have been evaluated. The numerical simulation was performed for maximum and minimum flows at the study reach to indicate the locations of deposition and erosion. According to NRI technical reports; as this cable is laid directly on the riverbed, it falls $25 \mathrm{~cm}$ below the bed as shown in Fig. 14.

Fig. 15 shows the predicated water depths, water velocities, and bed levels patterns for the initial river bed levels surveyed in 2016 and the predicted for the year 2030 in case of releasing discharges for maximum and minimum. As shown in Fig. 15a, as a result, after running the model for fourteen years, it is clear that the maximum erosion occurs when the maximum discharge is passed compared to minimum discharge, particularly at the location of the fiber cable that crosses the Nile. Furthermore, Fig. 15b, and 15c, the initial velocity distribution in 2016 ranges between 0.4 and $0.5(\mathrm{~m} / \mathrm{s})$.

The predicted velocity distribution in 2030 is high in the maximum case at many locations, particularly in outer curves regions, at the location of fiber cable, which ranges between 1.0 and $1.2(\mathrm{~m} / \mathrm{s})$. In the same pattern, the velocity distribution at the minimum case was introduced. It can be noted that in the case of maximum flow, erosion has a significant effect on the location of fiber cable path that crosses the Nile than sedimentation. As a result, this will affect the fiber optic cable path which crosses the Nile, especially in the case of maximum flow.

2) Scenario 2: Laying fiber optic cable along the riverbed. The model simulated laying the fiber optic cable along the bed of Nile River as shown in Fig. 16. In this scenario, a numerical simulation was performed for maximum and minimum flows at the upstream and water levels at the downstream boundary of the study reach.

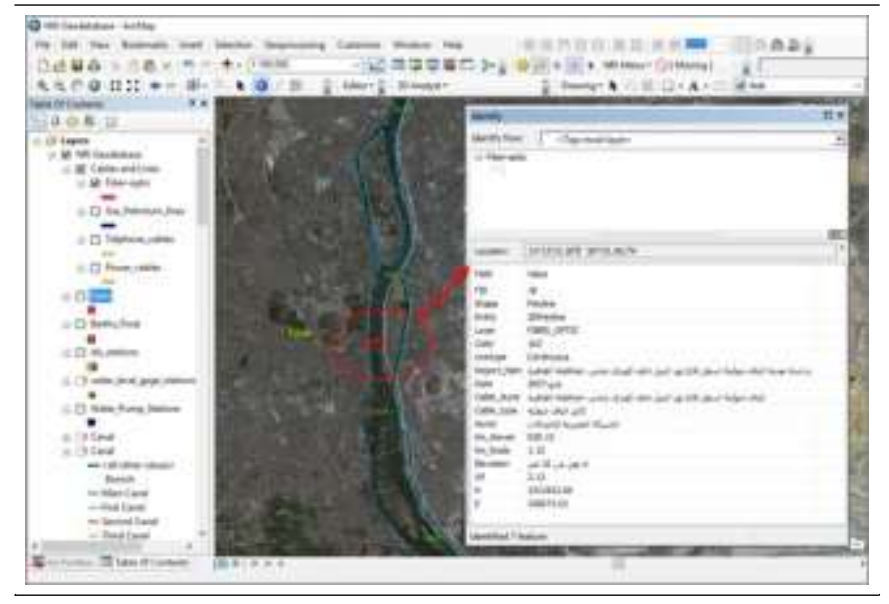

Fig. 13. Fiber Optic Cables Crossing Nile River.

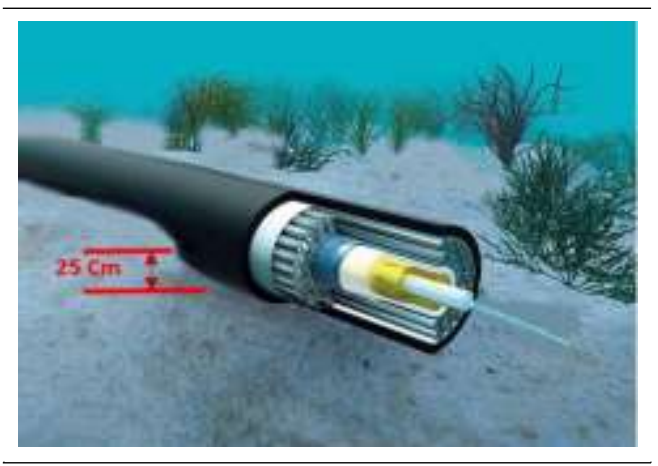

Fig. 14. Laying Fiber Optic Cable Directly on the Bed Level of Nile River. 

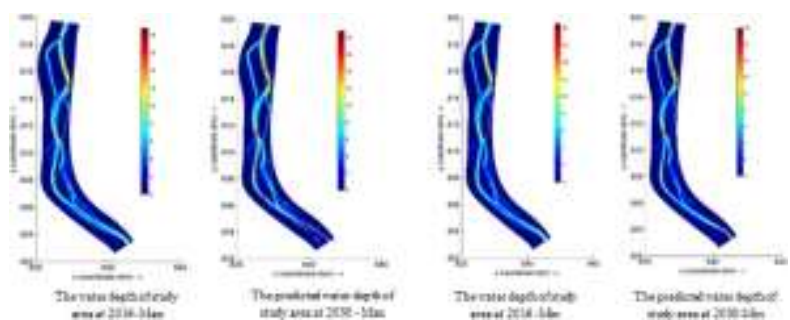

(a) Simulated Water Depths for Maximum and Minimum Discharge.
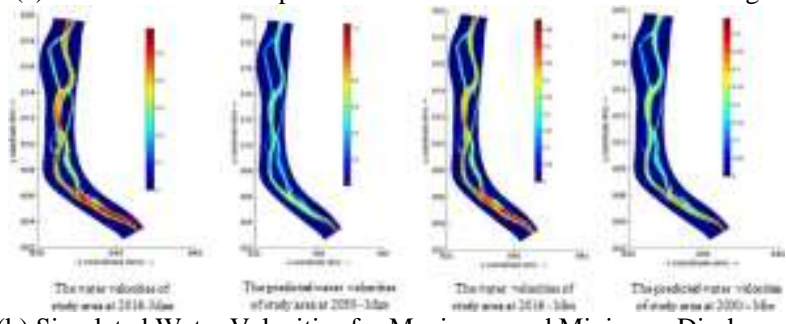

(b) Simulated Water Velocities for Maximum and Minimum Discharge.
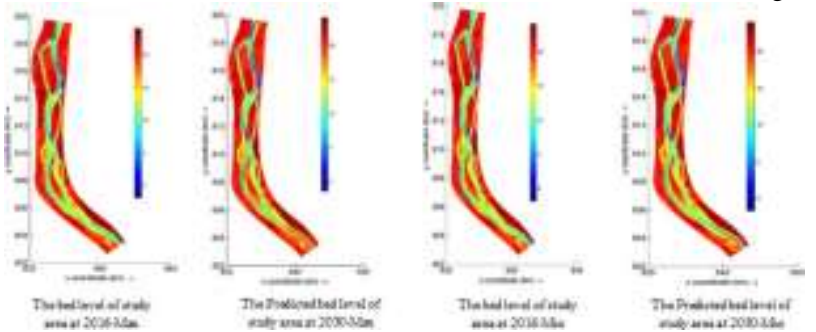

(c) Simulated Bed Levels for Maximum and Minimum Discharge

Fig. 15. Simulated Water Depths, Water Velocities, and Bed Levels Patterns for Scenario1.

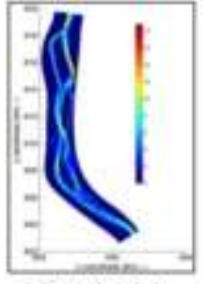

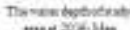

(a) Simulated

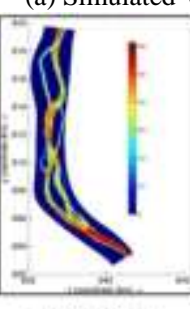

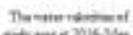

(b) Simulated Water Velocities for

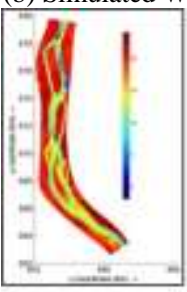

The bovivedritits
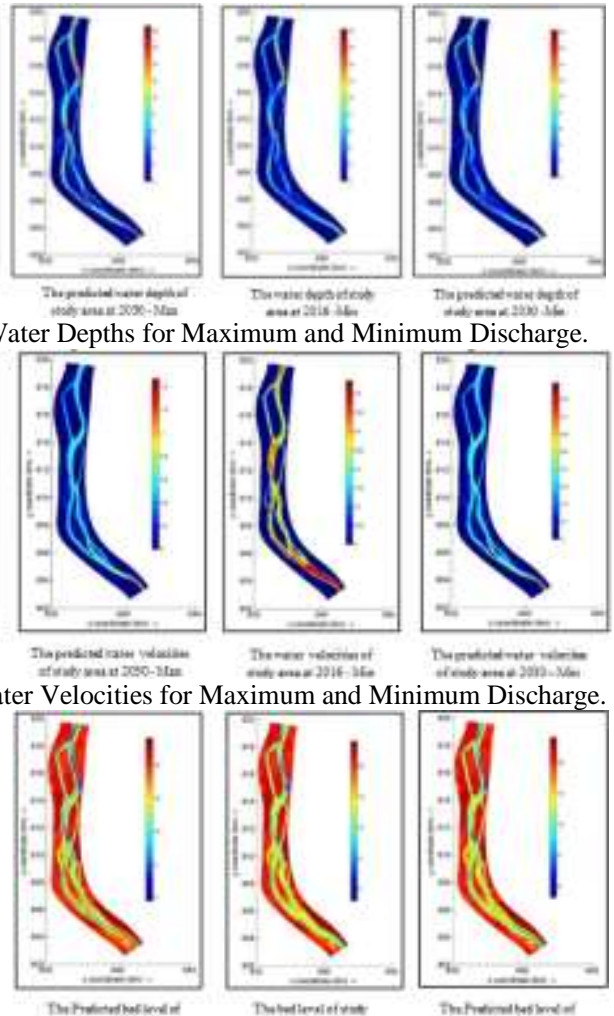

Thithicuthorimet

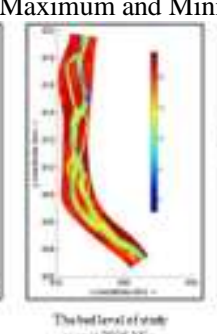

imum Discharge.

(c) Simulated Bed Levels for Maximum and Minimum Discharge.

Fig. 16. Simulated Water Depths, Water Velocities, and Bed Levels Patterns for Scenario 2

\section{RESULTS AND DISCUSSIONS}

The proposed fiber optic cable path is affected by certain factors related to river processes as maximum and minimum flow, erosion, and deposition. Hence, it is very important to simulate and check with different flow cases. Any changes in river morphology are prohibited unless they are of absolute importance such as maintenance operations. That is including pump intakes and pipeline crossing under the river. Fig. 17 shows the predicted max and min flow morphological changes in 2030 for the first scenario, where the fiber optic cable was laid by crossing Nile River at $\mathrm{km} 928.15$ downstream OAD through the tunnel drilling of the river for laying the fiber optic cable along the riverbed by $3(\mathrm{~m})$. It can be noted that the rate of erosion was greater than deposition, which could affect the safety and efficiency of the fiber optic cable.

On the other hand, Fig. 18 shows the longitudinal bed level profiles for both the initial riverbed in 2016 and the predicted in 2030 for the release of maximum and minimum flows for the second scenario, where the fiber optic cable is laid along the Nile River bed. It can be observed that in the first scenario, the erosion rate relative to the length of the cross-section area is greater in the second scenario. Also, in the first scenario, the deposition rate relative to the length of the cross-section is greater in the second scenario. It is clear that in scenario 1, the efficiency of the fiber optic cable path will be affected by the high erosion rate compared to the second scenario. Hence, it can be concluded that the proposed fiber-optic cable laying scenario 2 is better than scenario 1 .

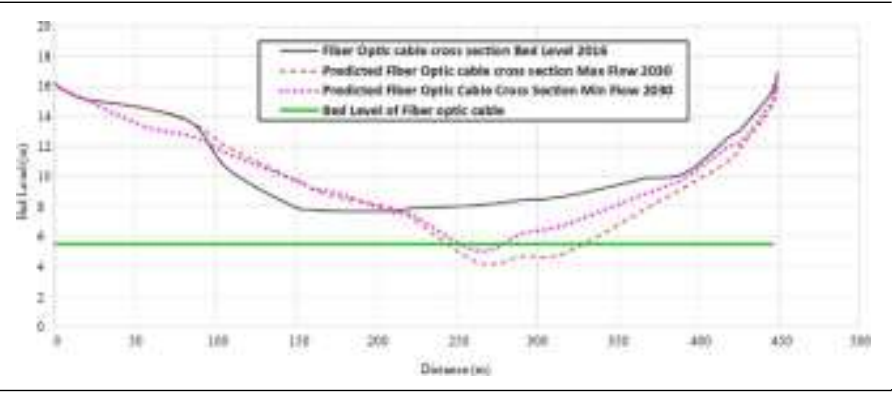

Fig. 17. Predicted Morphological Changes at Max and Min Flow (Scenario $1)$.

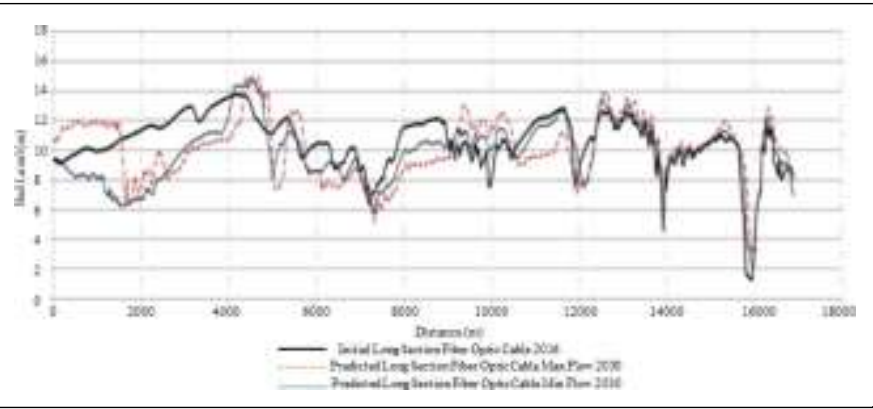

Fig. 18. Predicted Morphological Changes at Max and Min Flow (Scenario 2). 


\section{EVALUATING AND COMPARING THE ECONOMIC, ENVIRONMENTAL IMPACTS OF THE GROUND CABLES AND SUBMERGED CABLES UNDER THE NILE RIVER}

A comparison is introduced detailing the use of submerged river cables versus ground cables. It has been demonstrated that this type of network can be used with significant advantages over ground cable networks, especially for countries with long river lengths. While most Egyptian cities and towns are located deep inland to the west and south of the Mediterranean and the Red Sea coasts. There are many challenges facing ground fiber optic cable networks in Egypt. In particular, they involve high-cost drilling operations, especially when connecting cables to remote locations. Furthermore, they may suffer from loss of cables and equipment (e.g.: due to theft and vandalism). Besides, it is time-consuming and maintenance is costly. Moreover, there is a need for repeaters grid and Land permit costs for areas on which cable network is established. Table I shows these evaluations of economic and environmental impacts based on running costs, maintenance, repeaters, and power. According to this evaluation, a suitable proposal will be presented for the establishment of new fiber optic cable networks in Egypt submerged under the Nile River. Such networks could be considered as the core network of African countries especially those which are part of the Nile River basin.

TABLE I. ECONOMIC AND ENVIRONMENTAL IMPACTS COMPARISON BETWEEN THE GROUND AND SUBMERGED CABLES UNDER RIVER NILE

\begin{tabular}{|l|l|l|}
\hline $\begin{array}{l}\text { Economic/environmental } \\
\text { Impact Factor }\end{array}$ & $\begin{array}{l}\text { Ground Cables } \\
\text { Network }\end{array}$ & $\begin{array}{l}\text { Underwater Cables } \\
\text { Network }\end{array}$ \\
\hline Repeaters & Repeater grid & Repeater along River \\
\hline Power & Power grid & Power along River \\
\hline Theft & Frequently & Hardly \\
\hline Maintenance & $\begin{array}{l}\text { Time-consuming } \\
\text { and costly }\end{array}$ & rarely \\
\hline Security & Vulnerable & impervious \\
\hline Damage & vulnerable & impervious \\
\hline Human interventions & Frequent & Negligible \\
\hline Monitoring points & Difficult & Easy \\
\hline General Costs & High & Standard \\
\hline Land Cost & High & Standard \\
\hline Running cost & High & Standard \\
\hline Service Continuity & Low & High \\
\hline Materials & Standard & Standard \\
\hline Wars & Direct Effect & Negligible \\
\hline Temperature & High Effect & Low Effect \\
\hline Medium & ground & water \\
\hline Earthquakes & High Effect & Low Effect \\
\hline & & \\
\hline
\end{tabular}

\section{Proposed Nile River Fiber Optic CABle Features}

\section{A. Fiber Optic Cables}

Fiber Optic cabling has revolutionized the way that data travels globally. These cables are characterized by high- speed, which transmits data at much faster rates without any quality degradation compared to copper wires. Also, they contain an outer optical casing, which surrounds the light. The core can be configured in two different types:
1) Single-mode fiber optic cable: This type has a small core size (less than $10 \mu \mathrm{m}$ ) as shown in Fig. 19a. It allows the transmission of one light ray only. So, as the light passes through the single-mode fiber core, a little reflection of light is formed. This decreases fiber attenuation and further increases the signal's ability to travel. Thus, single-mode fibers are usually used in long distances up to $1000 \mathrm{~km}$ and high bandwidth applications.

2) Multimode fiber optic cable: Multimode fibers are characterized by larger cores $(62.5 \mu \mathrm{m}$ or $50 \mu \mathrm{m})$ - as shown in Fig. 19b - which introduce more data. This will allow more light reflections, and increase the rate of dispersion and attenuation, which may reduce the signal quality over long distances. Therefore, it can be noted that in short distances, multimode fibers are often preferred.

\section{B. Recommended Fiber Optic Cable}

According to the National Telecommunication Institute (NTI), Egypt, reports and recommendations, the recommended type of fiber optic cable (Fig. 20) Underwater / River crossing type optical fiber cable, based on ITU-T recommendations, IEC 60794, IEC 60332, IEC 304, or EIA/TIA-598 standards. This type of optical cable is characterized to be suitable for the transmission of voice, data, and broadband over long distances, and local area networks with installation methods underwater for river crossing [16].

The type of these cables marked by MLT (Multi-Loose Tube) design, high fiber capacities, Single-mode, multimode (50/125, 62.5/125), waterproof dry core design, high tensile strength, improved compressive strength, bituminized polypropylene yarns as an outer jacket.

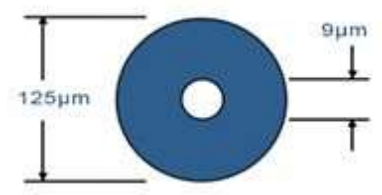

(a) Single-Mode Fiber-Optic Cable.

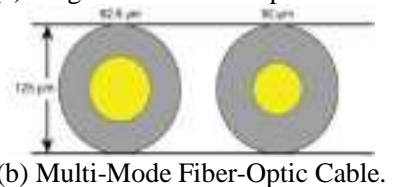

Fig. 19. Fiber Optic Cable Types.

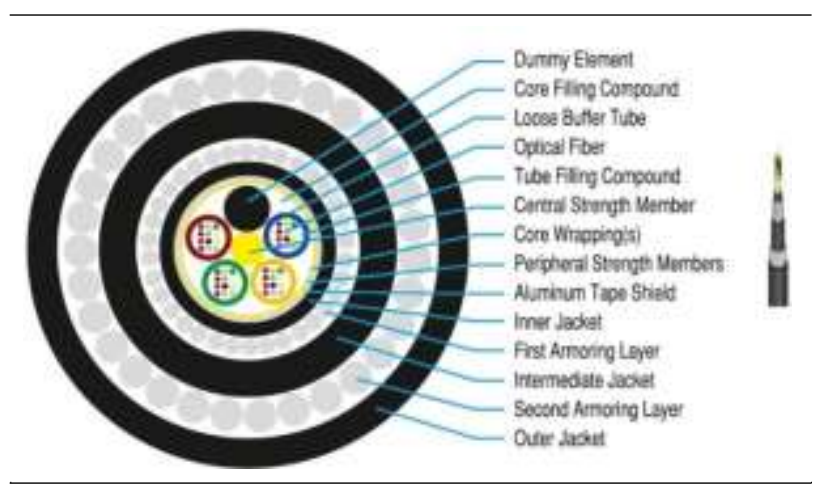

Fig. 20. Proposed Underwater Optical Fiber Cable. 
Based on the results and discussions of the Delft3D model, it can be concluded that it would be beneficial to consider constructing a fiber optic cable network along the bed of the Nile River to provide connectivity for inland cities. This infrastructure should be constructed as follows:

1) Installation of monitoring and control centers along the Nile River path for every $1000 \mathrm{~km}$. This distance is the longest distance that can be traveled by light through these cables before repeaters are required. Since the Nile River at the Egyptian border has a total length of $1440 \mathrm{~km}$, one repeater will be needed.

2) Installation of control centers can serve as checkpoints for other essential services such as water level measurements, water quality monitoring, and other public safety services.

3) Based on results and discussion; it is recommended that the second scenario be used to lay a fiber cable network along the riverbed in Egypt.

4) According to the recommendations of NTI, the singlemode fiber optic cable type (underwater / River crossing type optical fiber cable) should be used.

\section{CONCLUSION AND RECOMMENDATIONS}

It was noticed that the majority of fiber optic cable networks are established via submarine cables through the coastal areas. Constructed connections are not enough to connect inland towns and cities. This paper introduces a proposal to utilize the natural path of the Nile River in Egypt to construct a fiber optic cable system submerged under the river's water. This would provide coverage to inland areas that are located closer to riverbanks. Delft3D hydrodynamic model was used to simulate two different scenarios for laying fiber optic cable submerged under a riverbed in Egypt. Based on the results and discussions, it can be observed that in the first scenario, the erosion rate was greater than the deposition rate at the location of fiber optic cable compared to the second scenario. This could harm the safety and efficacy of the fiber optic cable. Furthermore, there are many issues with laying fiber optic cables across the Nile River. Several of these are the requirement of using more than one node over fiber optic cable for each. When the number of nodes increases, the cost of installation and drilling effort increases with each node. It can be concluded that scenario 2 is more suitable than scenario 1 for laying such cables along the Nile River in Egypt. Consequently, we found that it would be beneficial to consider constructing and installing a fiber optic cable network along the Nile riverbed to provide connectivity to inland cities. In this study, it is strongly recommended that a $\mathrm{n}$ action plan be developed for the proposed infrastructure as a fiber optic system along the Nile River. Finally, it is recommended to take into consideration the coordination with the affiliated authorities of public facilities and services that pass through the Nile River in Egypt to obtain all information about the locations and paths of these services such as gas lines, electricity, and phone cables.

\section{ACKNOWLEDGMENTS}

The authors thank Shimaa Badr, National Telecommunication Institute, Egypt for technical support.

\section{REFERENCES}

[1] Neal S Bergano. "Undersea fiber-optic cables make the web worldwide". In: 17th Opto- Electronics and Communications Conference (OECC 2012) Technical Digest. Busan, Korea, July 2012.

[2] C Jeffcoat, J Jackson, and J Ewald. "Considerations in Design and Laying a New Undersea Fiber Optic Cable." In: Challenges of Our Changing Global Environment. OCEANS '84 MTS/IEEE, 1984. DOI: DOI: 10. 1109 / oceans.1984.1152235.28.

[3] D Paul et al. "Undersea fiber optic cable communications system of the future: Operational, reliability, and systems considerations". In: IEEE journal of light technology 2.4 (1984), pp. 414-425.

[4] Y Iwamoto and H Fukinuki. "Recent advances in submarine optical fiber cable transmission systems in Japan”. In IEEE Journal of Lightwave Technology 3.5 (Oct. 1985), pp. 1005-1016.

[5] Y Namihira et al. "Dynamic polarization fluctuation characteristics of optical fiber submarine cables under various environmental conditions." In: Journal of Lightwave Technology 6(5) (1988), pp. 728-738. DOI: DOI: $10.1109 / 50.4059$.

[6] M R Harrison. "Installation and burial of a 240-kilometer long fiber optic telecommunication cable in the Bass Strait using the "ship-ofopportunity" installation technique". In: Challenges of Our Changing Global Environment. OCEANS '95 MTS/IEEE, 1995. DOI: DOI: 10.1109/oceans.1995.526760.

[7] $\mathrm{R}$ Butler. "Scientific re-use of retired undersea fiber optic telecommunications cables." In: International Conference Physics and Control. (Cat. No.03EX708), 2003. DOI: 10.1109/SSC.2003.1224153.

[8] Amir Hosseini, M K Ramezani, and M Banae. "Submarine cable installation between production platform and satellite wellhead platform of south pars gas field - phase 1 in the Persian Gulf'. In Challenges of Our Changing Global Environment. OCEANS '04 MTS/IEEE, 2004. DOI: DOI: 10. 1109 / oceans. 2004. 1402923.

[9] M P Wood and L Carter. "Whale Entanglements with Submarine Telecommunication Cables." In: IEEE Journal of Oceanic Engineering 33(4) (2008), pp. 445-450. DOI: doi:10.1109/joe.2008.2001638.

[10] Davide Brizzolara Davide Anguita and Giancarlo Par- ODI. "Design and Implementation of HDL Modules and Circuits for Underwater Optical Wireless Communication". International Conference on Telecommunications and Informatics. Springer (9), 2009, p. 132.

[11] Aditi and Preeti. "Submarine Optical Cables as a Key Component in Undersea Telecommunications: A Review”. In: International Journal of Application or Innovation in Engineering \& Management (IJAIEM) 1.4 (Dec. 2012), pp. 79-83.

[12] Navneet Agrawal and Ajay Kumar Vyas. "Submarines Optical communication: A research review". In: International Journal of Electronics and Computer Science Engineering 1.2 (2012), pp. 370-374.

[13] Siang-Chih Chan et al. "Preliminary plan of underwater environmental monitoring in the offshore wind farm in the western sea of Taiwan". In: Challenges of Our Changing Global Environment. MTS/IEEE OCEANS -Bergen, 2013. DOI: doi:10.1109/oceans- bergen.2013. 6608093.

[14] I. Jurdana and V. Sucic. "Submarine optical networks: How to make them greener". In: 16th International Conference on Transparent Optical Networks (ICTON). 2014. DOI: doi:10.1109/icon.2014.6876663.

[15] Ammar A. Saleh, Amin B. A. Mustafa, and Ashraf A Osman. "Feasibility of Laying Fiber-Optic Cables underwater along River Nile Basin- Sudan Study Case". In: IOSR Journal of Computer Engineering (IOSR-JCE).17.1 (Jan. 2015), pp. 2278-8727.

[16] Erik Agrell et al. "Roadmap of optical communications". In: Journal of Optics 18.40 (June 2016), pp. 1- 40. DOI:/ 10. 1088 / 2040 8978/18/6/063002. URL:https://creativecommons.org/licenses/by/4.0/.

[17] D L Msongaleli et al. "Disaster-Aware Submarine Fiber- Optic Cable Deployment for Mesh Networks." In: Journal of Lightwave Technology 34(18) (2016), pp. 4293-4303. DOI: doi:10.1109/jlt.2016.2587719.

[18] Abd-Elbaky, Mostafa, and Shuanggen Jin. "Estimating Runoff in the Nile River Basin from Multi-Satellite Measurements." In: 26th International Conference on Geoinformatics. 2018, pp. 1-5.

[19] Anna Tzanakaki et al. "Optical Network Design and Modeling”. In: Optical Network Design and Modeling: 23rd IFIP WG 6.10 International Conference, ONDM 2019, Athens, Greece, May 13-16, 
2019, Proceedings. Springer Nature, 2020.

[20] Tele-Geography. Submarine Cable Map. http:// www.subm arinecablemap .com / \# /country / sudan. last accessed April 2020.

[21] Mark Van. DeRee and P Eng. "Submarine Cable Installation Techniques and Alternatives", HEAVY MOV- ABLE STRUCTURES". In: 14th Biennial Movable Bridge Symposium. October 22 - 25, 2012, ORLANDO, FLORIDA. 